\title{
The motivational consequences of cholinergic stimulation of the medial septal area
}

\author{
DIANA L. KELLEY and DAMON MOUNTFORD* \\ University of Kansas, Lawrence, Kansas 66044
}

\begin{abstract}
Direct application of carbachol to the medial septal area of satiated rats produced large significant increases in drinking. Histamine produced a small and inconsistent increase in drinking, and isoproterenol produced an inconsistent decrease in eating. Carbachol-stimulated Ss performed significantly better on a brightness discrimination task than satiated controls, as measured by running and starting speeds, but did not differ from controls in number of correct choices.
\end{abstract}

Direct application of carbachol to a number of limbic system sites elicits drinking behavior in satiated rats (Grossman, 1960, 1964; Fisher \& Coury, 1962). Several investigators have suggested that stimulation of cholinergic pathways involved in normal thirst may produce the observed drinking behavior. If this hypothesis is correct, cholinergic thirst should demonstrate all of the motivational properties of normal thirst, e.g., the capacity to motivate the learning of a new response or the performance of a previously learned response for a water reward.

Grossman (1962) reported that carbachol stimulation of the lateral hypothalamus increased barpressing for a water reward. Khavari and Russell (1966) reported no difference between water-deprived and carbachol-stimulated rats in running speed in a straight alley for a water reward or in rate of acquisition of a T-maze task. This evidence suggests that cholinergic stimulation of the lateral hypothalamus produces thirst which possesses the motivational properties of deprivation-induced thirst.

Cholinergic stimulation of the medial septal area (MSA) has consistently produced large increases in drinking (Grossman, 1964; Mountford, 1969). The object of the present study was to investigate the motivational properties of thirst induced by cholinergic stimulation of the MSA. In Experiment 1, the effects upon food and water intake of cholinergic stimulation using carbachol were compared with the effects of stimulation using three candidate transmitter substances-norepinephrine, isoproterenol, and histamine. Experiment 2 tested the capacity of the thirst produced by cholinergic stimulation of the MSA to motivate the learning of a new response in a brightness discrimination task, for a water reward.

\section{METHOD}

\section{Subjects}

The Ss were 12 naive male Sprague-Dawley albino rats, 150 days old at the time of operation. A single double-walled cannula was permanently implanted in the MSA of each S [de Groot (1969) coordinates; Ap. 8.0, V 1.0, H 0.0]. Operative

*Damon Mountford may be contacted at 115 Meadowlane, Lansing, Kansas 66043. procedures followed Grossman (1960).

\section{Apparatus and Procedure}

Chemical stimulation procedures involved removing the inner cannula, cleaning it, tapping the crystalline drug into the tip, and then returning it to the implant site. Control stimulation was provided by following this same procedure, except no drug was used.

The apparatus consisted of a modified Grice box for brightness discrimination (Grice, 1948). There were three alleys, 25 in. long, with attached goalboxes, 15 in. long. The two outside alleys and goalboxes were light gray and the center alley and goalbox were black. The intermediate gray Y-shaped startbox led to two alleys. By sliding the startbox to the left and right, the brightnesses of the alleys could be reversed. Guillotine doors which prevented retracing were located at the startbox exit and goalbox entrances. Opening the startbox door activated the first Hunter Klockounter, which was stopped by breaking a photocell beam at the start of the alley. Breaking this photocell beam also started a second Hunter Klockounter, which was stopped when the animal broke a photocell beam located $1 \mathrm{in}$. from the goalbox door.

Experiment 1. Experimentation began 3 weeks after the operations. All Ss had continuous free access to food (Purina Lab Chow) and tap water. At the same time each day 1-h tests of food and water intake were given in the home cage until stable baselines of intake were established ( 3 consecutive days of no significant change in either food or water intake). The Ss were then administered each of the four drugs twice in a counterbalanced sequence. Each group of three Ss started the drug treatments (carbachol, histamine, norepinephrine, and isoproterenol) with a different drug. Two control test days preceded each drug test day. The average intake on the 2 control test days was subtracted from the intake on the succeeding test day to produce the difference scores used in all graphical presentations and statistical tests.

Experiment 2. During Experiment 1, two Ss died and one lost its cannula implant. The remaining nine Ss were randomly assigned to a control group (four Ss) and a carbachol-stimulation group (five Ss). During the experiment, carbachol was tapped into the cannula of each experimental $S$ and the $S$ was returned to its home cage for a 15 -min wait. No food or water were available in the home cage during this period. The procedure for control Ss was the same, except that no drug was administered. Each S was randomly assigned to either dark or light as the correct alley. The position of the correct alley-left or right-was varied according to the sequences: LRRLLRLRRL and RLLRRLRLLR. Each goalbox contained a drinking tube, but only the tube in the correct goalbox was filled. Each $\mathrm{S}$ received 10 consecutive daily 2 -min trials for 10 days. If $\mathrm{S}$ failed to enter the goalbox within $60 \mathrm{sec}$, no choice was recorded for that trial and the $\mathrm{S}$ was returned to a waiting cage. Starting and running times were converted to speed scores. The correct-choice data and speed scores were evaluated by analyses of variance for 


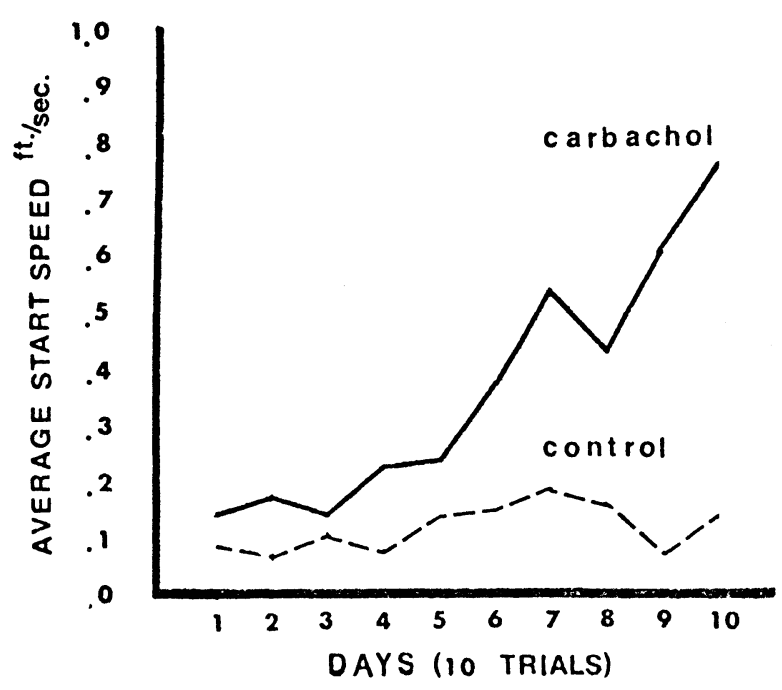

Fig. 1. Starting speeds for carbachol and control groups over 10 blocks of 10 trials.

repeated measures (Edwards, 1963).

At the end of Experiment 2, Ss were given $50 \mathrm{mg}$ of Nembutal IP and were perfused with $0.9 \%$ saline followed by $10 \%$ Formalin. Frozen sections of 50 microns thickness were cut from each brain in the region of the implant tip, affixed to slides with albumin, and stained with cresylechtviolet and luxol fast blue.

\section{RESULTS}

Eleven of the 12 intended MSA placements fell within the MSA. One cannula tip lay within the anterior thalamus. Only the data from the 11 Ss with MSA placements were included in the statistical analysis.

Significant increases in water intake followed both applications of carbachol to the MSA (Test 1, M = $19.63 \mathrm{cc}, \mathrm{t}=6.88, \mathrm{df}=8, \mathrm{p}<.01$; Test $2, \mathrm{M}=15.55 \mathrm{cc}$, $\mathrm{t}=5.69, \mathrm{df}=6, \mathrm{p}<.01)$. A significant increase in water intake followed the second application of histamine to the MSA $(M=3.48 \mathrm{cc}, \mathrm{t}=2.92$, df $=8, \mathrm{p}<.01)$. A significant decrease in food intake followed the first application of isoproterenol $(\mathrm{M}=-1.08 \mathrm{~g}, \mathrm{t}=-2.91 \mathrm{df}$ $=8, \mathrm{p}<.01)$. There were no other significant changes in food or water intake following any drug application.

The effect of carbachol on the number of correct choices was not significantly different from the control. Neither group differed significantly from chance level on this measure. The analysis did not indicate a reliable drug effect, trials effect, or Drug by Trial interaction.

Analysis of variance revealed a significant difference in starting speeds between the carbachol and control groups $(\mathrm{F}=11.66, \mathrm{df}=1 / 6, \mathrm{p}<.05)$. Figure 1 suggests that the carbachol group improved its starting speeds over the 100 trials while the control group showed almost no improvement. This Drugs by Trials interaction was significant $(F=2.25, \mathrm{df}=9 / 54, \mathrm{p}<.05)$, as was the trials effect $(\mathrm{F}=3.50, \mathrm{df}=9 / 54, \mathrm{p}<.01)$.

Analysis of running speeds revealed that differences due to drugs were significant for the last four blocks of trials $(F=6.24, d f=1 / 6, p<.05)$. Figure 2 suggests that the significant difference at the end of training was due to the gradual improvement of the carbachol group across trials. The trials effect was significant $(F=2.56$, df $=9 / 54, p<.05)$; however, the interaction of Drugs by Trials was not significant.

\section{DISCUSSION}

Cholinergic stimulation of the medial septal area significantly increased water intake from control levels. This result corroborates findings reported by Grossman (1964) and Fisher and Coury (1962). No other candidate transmitter produced a consistent change in drinking behavior. This suggests that the thirst-relevant sites in the MSA may be cholinergically specific. The small and inconsistent effect of histamine on water intake and isoproterenol on food intake may be due to chance fluctuations in intake or may suggest that the septal area is not the primary site of action for these drugs.

The results of Experiment 2 suggest that cholinergic pathways in MSA are involved in normal regulation of thirst. The significantly faster starting and running speeds among the cholinergically stimulated Ss suggest that these Ss were highly motivated to obtain water. General activation does not explain these results, since there was a significant increase in speed on these measures over 100 trials. In addition, Experiment 1 demonstrated the water-directed quality of this activity in the home cage.

While the cholinergically stimulated Ss apparently were motivated to learn the water-runway association, they showed no signs of learning the brightness-discrimination aspect of the task. The latter result might be explained if cholinergic stimulation of the MSA interfered with complex associations or memory processes. Grossman (1964) reported

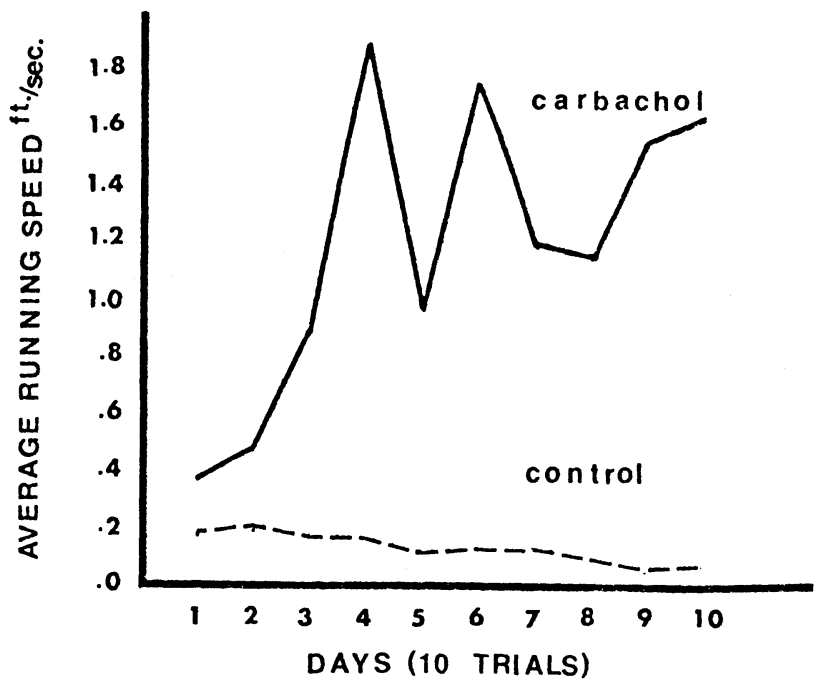

Fig. 2. Running speeds for carbachol and control groups over 10 blocks of 10 trials. 
interference with avoidance learning following cholinergic stimulation of the septal area.

Alternatively, the cholinergically stimulated Ss may have been overmotivated, which interfered with learning the discrimination. Bruner, Matter, and Papanek (1955) reported interference with discrimination learning following extended water deprivation. The large increases in drinking during Experiment 1 and the increasingly fast starting- and running-speed scores during Experiment 2 indicate a very high level of motivation for water among the cholinergically stimulated Ss.

\section{REFERENCES}

Bruner, J. S., Matter, J., \& Papanek, M. L. Breadth of learning as a function of drive level and mechanization. Psychological Review, 1955, 62, 1-10.

Edwards, A. L. Experimental design in psychological research.
New York: Holt, Rinehart \& Winston, 1962.

Fisher, A. E., \& Coury, J. N. Cholinergic tracing of a central neural circuit underlying the thirst drive. Science, 1962, 138 . 691-693.

Grice, R. G. The relation of secondary reinforcement to delayed reward in visual discrimination learning. Journal of Experimental Psychology, 1948, 38, 1-16.

Grossman, S. P. Eating or drinking elicited by direct adrenergic or cholinergic stimulation of hypothalamus. Science, 1960, 132, 301-302.

Grossman, S. P. Direct adrenergic and cholinergic stimulation of hypothalamic mechanisms. American Journal of Physiology, $1962,202,872-882$.

Grossman, S. P. Effect of chemical stimulation of the septal area on motivation. Journal of Comparative \& Physiological Psychology, 1964, 58, 194-200.

Khavari, K. A., \& Russell, R. W. Acquisition, retention and extinction under conditions of water deprivation and of central cholinergic stimulation. Journal of Comparative \& Physiological Psy chology, 1966, 61, 339-345.

Mountford, D. Alterations in drinking following isoproterenol stimulation of hippocampus. Physiologist, 1969, 12, 309.

(Received for publication February 12, 1973; revision received November 19,1973 .) 